Review began 11/02/2021 Review ended 11/10/2021 Published 11/14/2021

๑) Copyright 2021

Al- Shehri et al. This is an open access article distributed under the terms of the Creative Commons Attribution License CCBY 4.0., which permits unrestricted use, distribution, and reproduction in any medium, provided the original author and source are credited.

\section{Association Between Acute Otitis Media and Inner Ear Disorders Among Adults in Aseer Region}

Ali Maeed Al- Shehri Sr. ${ }^{1}$, Ahmed S. AL-Zomia ${ }^{2}$, Ahmed F. Alayash ${ }^{2}$, Aljohrah M. Al Hunaif ${ }^{1}$, Abdulrhman A. Mansour ${ }^{1}$, Mushary Alqahtani ${ }^{3}$, Omar A. Asiri ${ }^{1}$, Saeed A. Alserhan ${ }^{1}$

1. ENT, College of Medicine, King Khalid University (KKU), Abha, SAU 2. Surgery, College of Medicine, King Khalid University (KKU), Abha, SAU 3. Medicine, College of Medicine, King Khalid University (KKU), Abha, SAU

Corresponding author: Ali Maeed Al- Shehri Sr., amsalshehri@kku.edu.sa

\section{Abstract}

\section{Introduction}

Acute otitis media (AOM) is an infection of the middle ear that produces pain, fever, and discharge, as well as hearing loss. It is one of the most common problems that pediatricians encounter. Almost $80 \%$ of children have had at least one episode of AOM, and between $80 \%$ and $90 \%$ have had at least one episode of otitis media with effusion before entering school.

\section{Methods}

The cross-sectional study is conducted among male and female patients, adults, and children who visited two of the largest government hospitals in the Aseer region in Southern Saudi Arabia (Aseer Central Hospital and Khamis Mushait General Hospital). The children and adults with AOM who visited the hospitals were traced by searching the medical record system by the keyword "acute otitis media." Two authors extracted data from the medical record and patients. After extracting data, the patient will be called through mobile phone to invite them to participate in the study. If the patient agrees to participate, she/he would be sent through email link containing an encrypted and high-security electronic signature to obtain his/her consent.

\section{Conclusion}

One of the most common pediatric infections is otitis media (inflammation of the middle ear). Children are more often than adults to get otitis media, and the majority of cases are treated with antibiotics. Clinicians commonly miss the acute stage of the disease, especially in children under the age of five. Delay or omission of diagnoses leads to inefficient management and an increased risk of negative effects.

Categories: Ophthalmology, Otolaryngology, Other

Keywords: treatment, symptoms, pain, diseases, otitis media

\section{Introduction}

Acute otitis media (AOM) is a middle ear infection that causes discomfort, fever, and occasional discharge, as well as hearing loss (Zakzouk et al., 2002) [1]. Around $80 \%$ of children have at least one episode of AOM [2]. In one study, 80-90\% of the subjects had at least one episode of otitis media [3]. One study stated that acute suppurative otitis media (ASOM) usually causes severe deep ear pain [4]. As per research, purulence in the middle ear is also present in the mastoid air cells because they are connected $[5,6]$.

According to one study, AOM may be complicated by an inner ear disorder (IED), which damages the basal cochlear turn (localized serous or toxic labyrinthitis) [6]. A Korean study discovered an incidence of $9.6 \%$ in 75 patients with $\mathrm{AOM}$, with sensorineural hearing loss (SNHL) occurring within zero to 10 days of AOM onset and regularly beginning with high-frequency hearing loss [7]. In Saudi Arabia, the number of incidences of AOM in children varies in different provinces, with the southern and central provinces having the highest frequency [8]. The incidence was more significant in young children under four years and decreased in children aged eight to 12 years [9]. Male children had a slightly higher rate of AOM than female children (1.36\% vs. $0.80 \%)$ [10].

According to one study, there are several universally accepted risk factors for AOM, including allergies, craniofacial deformities, iron deficiency, passive smoking, and hypertrophic adenoids [11]. Mastoiditis, a severe bacterial infection affecting the mastoid bone behind the ear, is the most prevalent complication currently. Infection of the inner ear is most typically observed in people who do not have otitis media [12]. It is frequently self-limited and linked with a nonspecific viral disease [13]. When it comes to otitis media, though it's usually a bacterial infection that has to be treated quickly. 


\section{Cureus}

\section{Materials And Methods}

The cross-sectional study was conducted among patients - male and female, adults and children - who visited two of the largest government hospitals in the Aseer region in Southern Saudi Arabia (Aseer Central Hospital and Khamis Mushait General Hospital). The children and adults with AOM who visited the hospitals were traced by searching the medical record system using the "acute otitis media." Two authors extracted data from the medical record and patients. After extracting the data, the patient will be called by mobile phone to invite them to participate in the study. If the patient agrees to participate, she/he would be sent an email link containing an encrypted and high-security electronic signature to obtain his/her consent. After the consent is electronically signed, the patient will be asked about presenting symptoms of AOM, and all relevant clinical data, which will be stored in an encrypted electronic data capture system (Castor EDC ${ }^{\circledR}$ ). If the patient refuses to participate, we will not collect his or her data.

Regarding the questionnaire, it was constructed by a panel of experts after the discussions. Statistical analysis was performed using SPSS version 26.0 software (Armonk, NY: IBM Corp.). Categorical variables are presented using descriptive statistics, including total numbers and percentages. Comparisons between categorical variables are analyzed using a chi-square test. Continuous variables are presented as means with standard deviation (SD). A p-value $<0.05$ is considered statistically significant. The sampling technique was a convenient method of sampling, with those who had visited hospitals with ear diseases during the study period being included in this study. The study was approved by the general directors of the health affairsAseer region KSA. IRB approval number REC-No (14-07-2021).

\section{Results}

Out of 229 respondents, $37.1 \%$ were females while $62.9 \%$ were males; $48.8 \%$ had a university-level education, $63.3 \%$ were married, and $36.7 \%$ were single; $46.3 \%$ had diseases related to the nose, $93.4 \%$ were Saudi and 6.6\% were non-Saudi; $21.8 \%$ were unemployed, and $89.5 \%$ were from the Aseer region (Table 1). In our study, we observed that $34.9 \%$ have inner ear diseases, $59.8 \%$ have pain in the ear, and $52.0 \%$ have suffered from complications after the middle ear infection. The majority of the respondents (81.2\%) had a disability due to otitis media for less than six months. In our research, $48.0 \%$ of the infection period was last year (Tables 2-5).

\begin{tabular}{|c|c|c|}
\hline Demographic variables & Frequency & $\%$ \\
\hline \multicolumn{3}{|l|}{ Do you suffer from any disease in the nose? } \\
\hline No & 123 & 53.7 \\
\hline Yes Yes & 106 & 46.3 \\
\hline \multicolumn{3}{|l|}{ Nationality } \\
\hline Non -Saudi & 15 & 6.6 \\
\hline Saudi & 214 & 93.4 \\
\hline \multicolumn{3}{|l|}{ Occupation } \\
\hline Army & 24 & 10.5 \\
\hline Bachelor's degree in Information Systems & 1 & 0.4 \\
\hline Doctor & 10 & 4.4 \\
\hline Engineer & 5 & 2.2 \\
\hline Freelancing & 1 & 0.4 \\
\hline Government employee & 34 & 14.8 \\
\hline Health educator & 1 & 0.4 \\
\hline Housewife & 6 & 2.6 \\
\hline Nurse & 1 & 0.4 \\
\hline Public sector & 2 & 0.9 \\
\hline Private Sector & 8 & 3.5 \\
\hline Retired & 10 & 4.4 \\
\hline Student & 45 & 19.7 \\
\hline
\end{tabular}




\section{Cureus}

\begin{tabular}{|c|c|c|}
\hline Teacher & 29 & 12.7 \\
\hline Unemployed & 50 & 21.8 \\
\hline Worker & 2 & 0.9 \\
\hline \multicolumn{3}{|l|}{ Residence } \\
\hline Aseer Region & 205 & 89.5 \\
\hline Outside the Aseer region & 24 & 10.5 \\
\hline Total & 229 & 100.0 \\
\hline \multicolumn{3}{|l|}{ Marital status } \\
\hline Married & 145 & 63.3 \\
\hline Single & 84 & 36.7 \\
\hline \multicolumn{3}{|l|}{ Age (years) } \\
\hline$>60$ & 16 & 7.0 \\
\hline $19-29$ & 51 & 22.3 \\
\hline $30-39$ & 67 & 29.3 \\
\hline $40-49$ & 42 & 18.3 \\
\hline $50-59$ & 24 & 10.5 \\
\hline $6-18$ & 29 & 12.7 \\
\hline \multicolumn{3}{|l|}{ Education } \\
\hline Diploma & 2 & 0.9 \\
\hline Elementary or lower & 44 & 19.2 \\
\hline Middle & 22 & 9.6 \\
\hline Postgraduate & 20 & 8.7 \\
\hline Secondary & 43 & 18.8 \\
\hline University & 98 & 42.8 \\
\hline \multicolumn{3}{|l|}{ Gender } \\
\hline Female & 85 & 37.1 \\
\hline Male & 144 & 62.9 \\
\hline
\end{tabular}

TABLE 1: Demographic variables 


\section{Cureus}

Items related to pain

Frequency

$\%$

Do you suffer from diseases of the inner ear?

No

Yes

Is there pain in the ear?

No

Yes

Have you suffered from complications after the infection of the middle ear?

No

Yes
149

80

137

110

119
48.0

65.1

52.0

TABLE 2: Items related to pain

\begin{tabular}{|c|c|c|}
\hline How long have you been diagnosed with otitis media? & Frequency & $\%$ \\
\hline 14 years & 1 & 0.4 \\
\hline 20 years & 1 & 0.4 \\
\hline 30 years & 1 & 0.4 \\
\hline 6 months to 1 year & 29 & 12.7 \\
\hline 6 years & 3 & 1.3 \\
\hline 7 years & 1 & 0.4 \\
\hline 8 years & 1 & 0.4 \\
\hline Less than 6 months & 186 & 81.2 \\
\hline No & 6 & 2.6 \\
\hline Total & 229 & 100.0 \\
\hline
\end{tabular}

TABLE 3: Diagnostic period of otitis media

\begin{tabular}{|c|c|c|}
\hline What type of otitis media do you have? & Frequency & $\%$ \\
\hline Acute non-purulent otitis media & 21 & 9.2 \\
\hline Acute suppurative otitis media & 29 & 12.7 \\
\hline Otitis media with no effusion & 27 & 11.8 \\
\hline Otitis media, unspecified & 152 & 66.4 \\
\hline Total & 229 & 100.0 \\
\hline TABLE 4: Types of otitis me & & \\
\hline
\end{tabular}




\section{Cureus}

What symptoms have you been complaining about? (more than one answer can be chosen)

Difficulty hearing or not responding to sounds

Difficulty hearing or not responding to sounds loss of balance, headache

Ear pain, but when lying down, difficulty sleeping, irritability, fever of $38^{\circ} \mathrm{C}$ or more, fluid draining from the ear

Ear pain, especially when lying down, difficulty sleeping, difficulty hearing or not responding to sounds fluid discharge from the ear

Ear pain, especially when lying down, difficulty sleeping, difficulty hearing or not responding to sounds loss of balance, headache, pain in joints and bones

Ear pain, especially when lying down, difficulty sleeping, fever of $38^{\circ} \mathrm{C}$ or more, fluid drainage from the ear

Loss of balance, headache

No Symptoms
Frequency

1

2

0.4

2

TABLE 5: Symptoms of acute otitis media

We have observed that $59.8 \%$ were using cotton sticks for cleaning (Table 6); $34.1 \%$ were using antibiotics while $1.2 \%$ were using multiple treatments. We have noticed that $66.4 \%$ have unspecified otitis media, $11.8 \%$ have operation theater (OT) with no effusion, $12.7 \%$ have acute superlative OT, and $9.2 \%$ have acute nonpurulent OT (Tables 7,8 ). As per the data in Table 8 , we did not observe any significant differences while comparing resident status with nose diseases. Significant differences between types of OT and inner ear diseases were observed. 


\section{Cureus}

\begin{tabular}{|c|c|c|}
\hline What treatment have you been given for this infection? (more than one answer can be chosen) & Frequency & $\%$ \\
\hline Vitamin B12 drops, all of the above & 1 & 0.4 \\
\hline Antibiotics & 78 & 34.1 \\
\hline Antibiotics, all of the above & 2 & 0.9 \\
\hline Antibiotics, aspiration of fluids through the ear canal & 8 & 3.5 \\
\hline Antibiotics, drops & 1 & 0.4 \\
\hline Antibiotics, I didn't take any medicine & 1 & 0.4 \\
\hline Antibiotics, pain reliever, aspiration of fluid through the ear canal & 16 & 7.0 \\
\hline Antibiotics, pain reliever, aspiration of fluid through the ear canal, all of the above & 5 & 2.2 \\
\hline Antibiotics, pain reliever, aspiration of fluid through the ear canal, all of the above, B12 vitamin & 1 & 0.4 \\
\hline Aspiration of fluid through the ear canal & 5 & 2.2 \\
\hline Drops & 3 & 1.3 \\
\hline I didn't take any medicine & 20 & 8.7 \\
\hline I didn't take any nougat & 3 & 1.3 \\
\hline No treatment & 31 & 13.5 \\
\hline No, aspiration of fluid through the ear canal & 2 & 0.9 \\
\hline Operation & 1 & 0.4 \\
\hline Panadol & 1 & 0.4 \\
\hline Surgery & 5 & 2.2 \\
\hline Surgery & 1 & 0.4 \\
\hline Multiple treatm & 44 & 19.2 \\
\hline
\end{tabular}

TABLE 6: Treatments that have been given for the infection

\begin{tabular}{|c|c|c|c|c|c|}
\hline \multicolumn{2}{|c|}{ Do you suffer from any disease in the nose? } & No & Yes & Total & p-Value \\
\hline \multirow{2}{*}{ Residence } & Aseer region & 108 & 97 & 205 & \multirow{3}{*}{0.361} \\
\hline & Outside the Aseer region & 15 & 9 & 24 & \\
\hline Total & & 123 & 106 & 229 & \\
\hline
\end{tabular}

TABLE 7: Comparison between nose disease with resident status 


\section{Cureus}

\begin{tabular}{|c|c|c|c|c|}
\hline \multirow{2}{*}{ What type of otitis media do you have? } & \multicolumn{2}{|c|}{ Do you suffer from diseases of the inner ear? } & \multirow{2}{*}{ Total } & \multirow{2}{*}{ p-Value } \\
\hline & No & Yes & & \\
\hline Acute non-purulent otitis media & 13 & 8 & 21 & \multirow{4}{*}{0.018} \\
\hline Acute suppurative otitis media & 17 & 12 & 29 & \\
\hline Otitis media with no effusion & 11 & 16 & 27 & \\
\hline Otitis media, unspecified & 108 & 44 & 152 & \\
\hline
\end{tabular}

TABLE 8: Comparisons between type of OT media and inner ear diseases

OT: operation theater

\section{Discussion}

For this study, 229 patients were recruited from two public hospitals between March 2019 and February 2020 for the purpose to assess the incidences of various forms of AOM. Surprisingly, the occurrence of IED in AOM has only been recorded in animal studies, histological and clinical case reports, and case series, while epidemiological data on the incidence of IED in AOM is sparse [14,15]. In fact, the authors found only one study that determined the incidence of IED in AOM in a clinical setting, which retrospectively analyzed the cases of 75 adult patients (83 ears) with AOM from a secondary referral hospital and found an SNHL in 9.6\% of cases (eight ears), using rather strict SNHL inclusion criteria (bone conduction $\{\mathrm{BC}\}$ loss of $30 \mathrm{~dB}$ in three frequencies in comparison to the opposite normal ear) [14].

In our study, we found that patients were taking antibiotics, which is consistent with other studies' findings. According to a meta-analysis of randomized studies, antibiotics are most beneficial in children under the age of two years who have bilateral acute otitis media, but not in children who have acute otitis media with otorrhea [16]. Antibiotics are advised for all infants under the age of six months, children aged six months to two years when the diagnosis is certain, and children aged two years and older who have a serious infection (defined as moderate to severe otalgia or a temperature of more than $102.2^{\circ} \mathrm{F}$ ) [15]. According to our research, earache, ear discharge, hearing loss, ear-popping, ear fullness, dizziness, and fever are all indications of otitis media.

\section{Conclusions}

Otitis media (inflammation of the middle ear) is one of the most common pediatric infections. Children are more susceptible to otitis media than adults, while most cases are treated with antibiotics.

Clinicians often miss the acute phase of the disease. Diagnoses that are delayed or overlooked result in ineffective management and an increased risk of consequences. Parents will take care of their kids and give full and immediate attention to avoid further complications. The use of antibiotics is also helpful, however, only after the recommendations of the concerned doctor. Future studies are also required to explore further and educate the family to fulfill their responsibilities more appropriately.

\section{Additional Information \\ Disclosures}

Human subjects: Consent was obtained or waived by all participants in this study. General Directorate of Health Affairs - Aseer Region issued approval REC No. H-06B-091. Animal subjects: All authors have confirmed that this study did not involve animal subjects or tissue. Conflicts of interest: In compliance with the ICMJE uniform disclosure form, all authors declare the following: Payment/services info: All authors have declared that no financial support was received from any organization for the submitted work. Financial relationships: All authors have declared that they have no financial relationships at present or within the previous three years with any organizations that might have an interest in the submitted work. Other relationships: All authors have declared that there are no other relationships or activities that could appear to have influenced the submitted work.

\section{References}

1. University of Michigan Health System otitis media guideline . (2013). Accessed: May 16, 2013: http://www.med.umich.edu/1info/fhp/practiceguides/om/OM.pdf.

2. Usonis V, Jackowska T, Petraitiene $\mathrm{S}$, et al.: Incidence of acute otitis media in children below 6 years of age seen in medical practices in five East European countries. BMC Pediatr. 2016, 16:10.1186/s12887-016-06382

3. Hydén D, Ákerlind B, Peebo M: Inner ear and facial nerve complications of acute otitis media with focus on 
bacteriology and virology. Acta Otolaryngol. 2006, 126:460-6. 10.1080/00016480500401043

4. Kaya S, Tsuprun V, Hizli O, Schachern PA, Paparella MM, Cureoglu S: Cochlear changes in serous labyrinthitis associated with silent otitis media: a human temporal bone study. Am J Otolaryngol. 2016, 37:83-8. 10.1016/j.amjoto.2015.10.002

5. Kitsko DJ, Dohar JE: Inner ear and facial nerve complications of acute otitis media, including vertigo . Curr Allergy Asthma Rep. 2007, 7:444-50. 10.1007/s11882-007-0068-1

6. Paparella MM, Morizono T, Le CT, et al.: Sensorineural hearing loss in otitis media . Ann Otol Rhinol Laryngol. 1984, 93:623-9. 10.1177/000348948409300616

7. Park JH, Park SJ, Kim YH, Park MH: Sensorineural hearing loss: a complication of acute otitis media in adults. Eur Arch Otorhinolaryngol. 2014, 271:1879-84. 10.1007/s00405-013-2675-x

8. Tos M: Epidemiology and natural history of secretory otitis . Am J Otol. 1984, 5:459-62.

9. Zakzouk SM, Jamal TS, Daghistani KJ: Epidemiology of acute otitis media among Saudi children . Int J Pediatr Otorhinolaryngol. 2002, 62:219-22. 10.1016/s0165-5876(01)00617-6

10. Monasta L, Ronfani L, Marchetti F, et al.: Burden of disease caused by otitis media: systematic review and global estimates. PloS One. 2012, 7:10.1371/journal.pone.0036226

11. The 100 most common ICD-10 codes and short texts (by subject group) 1st quarter 2017 . Accessed: August 12, 2019: https://docplayer-org.translate.goog/69781833-Die-100-haeufigsten-icd-10-schluessel-undkurztexte-nach-fachgruppen-1-....

12. Löwenberg B: Influenza otitis in 1891. Trans Am Otol Soc. 1891, 5:70-83.

13. Milligan W: Haemorrhagic types of ear disease occurring during epidemics of influenza . J Laryngol Otol. 1926, 41:493-8.

14. Zenner HP: Practical Therapy of Ear, Nose and Throat Diseases. [Book in German] . Schattauer Verlag, Stuttgart, Germany; 2012.

15. Roberts DB: The etiology of bullous myringitis and the role of mycoplasmas in ear disease: a review . Pediatrics. 1980, 65:761-6.

16. Marais J, Dale BA: Bullous myringitis: a review. Clin Otolaryngol Allied Sci. 1997, 22:497-9. 10.1046/j.13652273.1997.00069.x 